\title{
Limited Awareness of Hepatitis B but Widespread Recognition of Its Sequelae in Rural Senegal: A Qualitative Study
}

\author{
Sokhna Boye, ${ }^{1}$ Yusuke Shimakawa, ${ }^{2}$ Muriel Vray, ${ }^{1,3}$ and Tamara Giles-Vernick ${ }^{4 *}$ \\ ${ }^{1}$ Unité d'Epidémiologie des Maladies Infectieuses, Institut Pasteur de Dakar, Dakar, Senegal; ${ }^{2}$ Emerging Diseases Epidemiology Unit, Pasteur \\ Institute, Paris, France; ${ }^{3}$ National Institute of Health and Medical Research (INSERM), Paris, France; ${ }^{4}$ Anthropology and Ecology of Disease
} Emergence Unit, Pasteur Institute, Paris, France

\begin{abstract}
To achieve the WHO's global strategy of eliminating hepatitis B virus (HBV) infection, it is essential to ensure adequate understanding of hepatitis $B$ disease to facilitate uptake of screening, linkage to care, and adherence to antiviral therapy. Sub-Saharan Africa has the world's highest prevalence of HBV infection, yet less than 1\% of HBV-infected people have been diagnosed. Lay populations do not widely recognize "hepatitis B." Hypothesizing that visible signs and symptoms of chronic HBV infection sequelae (jaundice, ascites, or cachexia) might be more easily recognizable, we conducted a qualitative study to determine how rural populations in Senegal understood these sequelae. We led six focus groups and 149 individual interviews with lay populations and formal and informal health workers in three rural study sites in Senegal. Only a third of lay populations (30/105) had ever heard of "hepatitis B," nor did they evoke local language diagnostic terms resembling this illness. Nevertheless, more than two-thirds (71/105) recognized signs and symptoms of end-stage liver disease but considered these physical manifestations to be a consequence of the manipulation of occult forces. Lay populations also contended that traditional healers, not formal medical structures, should treat such illnesses. Formal and informal health workers had limited knowledge about hepatitis B and difficulties identifying terms in local languages to explain the disease. Communication strategies based on the population's widespread recognition of the hepatitis sequelae may enhance awareness of hepatitis, which is a crucial element to increase screening uptake, linkage to care, and commitment to lifelong treatment in African communities.
\end{abstract}

\section{INTRODUCTION}

Chronic infection with hepatitis B virus (HBV) imposes a high disease burden around the world, thus representing an important global health priority. Recently, the WHO developed a global elimination strategy to reduce by 2030 the incidence of chronic HBV infection by $90 \%$ and its mortality by $65 \% .{ }^{1}$ By the same year, it also seeks to increase treatment uptake among infected people eligible for antiviral therapy from $8 \%$ in 2015 to $80 \%$. To accomplish these goals, investment in and scale-up of screening and treatment services will be crucial. ${ }^{2}$ So too will ensuring people's understanding of the disease and its medical testing and treatment, to facilitate uptake of screening, high linkage to care, and lifelong adherence to antiviral treatment for those needing it. .,4 $^{3}$

Sub-Saharan Africa has the highest prevalence of chronic HBV infection in the world. ${ }^{5,6}$ According to WHO estimates, however, less than $1 \%$ of HBV-infected people there have been diagnosed. ${ }^{2}$ Because its populations faced widespread exposure to the virus at birth or during childhood before the introduction of hepatitis B vaccination, ${ }^{7,8} \mathrm{HBV}$ infection screening in sub-Saharan Africa should target the entire adult population, rather than high-risk groups. ${ }^{3,9}$ Yet full population screening poses considerable challenges because "hepatitis B" is not well known among lay African populations. Previous sub-Saharan African studies have found a lack of recognition of the term "hepatitis B" among lay publics and limited knowledge among health-care workers, for which there are numerous reasons. ${ }^{9-17}$ The natural history of chronic HBV infection is complex: following exposure to HBV at birth or during early childhood, a lengthy period ensues during which chronic HBV infection is asymptomatic until the development

* Address correspondence to Tamara Giles-Vernick, Anthropology and Ecology of Disease Emergence, Pasteur Institute, 25-28 Rue du Docteur Roux, Paris 75724, France. E-mail: tamara.giles-vernick@pasteur.fr of end-stage liver disease (jaundice, ascites, hematemesis, and weight loss). ${ }^{18,19}$

Nonetheless, because signs and symptoms of end-stage liver disease are visible, understanding how African lay populations explain these physical symptoms would be useful. A recent systematic review evaluating hepatitis $B$-associated stigma did not identify research on African lay perceptions of these manifestations. ${ }^{20}$ We therefore undertook a qualitative study targeting lay populations, informal health workers, and formal primary care professionals in three regions of Senegal, a country with high HBV prevalence (11\% in adults). ${ }^{5}$ We sought to evaluate how these groups explained these signs and symptoms and to examine whether they knew the term "hepatitis B" and could describe this disease. We conducted this investigation to provide the foundations for strengthening communications strategies to enhance scale-up of screening and treatment services in Senegal and other African countries. ${ }^{14}$

\section{MATERIALS AND METHODS}

Study setting. Senegal ranks among the world's poorest countries, at 164th of $189 .{ }^{21}$ We selected three regions in Senegal (Niakhar, Bandafassi, and Mlomp) because they contain populations with wide-ranging livelihood practices and limited access to formal health care (Figure 1). The Niakhar region, $165 \mathrm{~km}$ from Senegal's capital, Dakar, is populated largely by Serer populations practicing mixed agriculture. The Bandafassi region, over $700 \mathrm{~km}$ southeast of Dakar and home primarily to Bédik, Fulbé, and migrant populations, engages in multiple livelihood practices: gold mining, farming, and animal husbandry. The Mlomp region, $450 \mathrm{~km}$ south of Dakar, engages in fishing and agriculture and has an active tourism industry. Populated predominantly by Djola speakers, it is also home to Manding and Fulbé peoples.

Senegal has 50 health districts, each with at least one health center led by a medical doctor and supported by health posts 


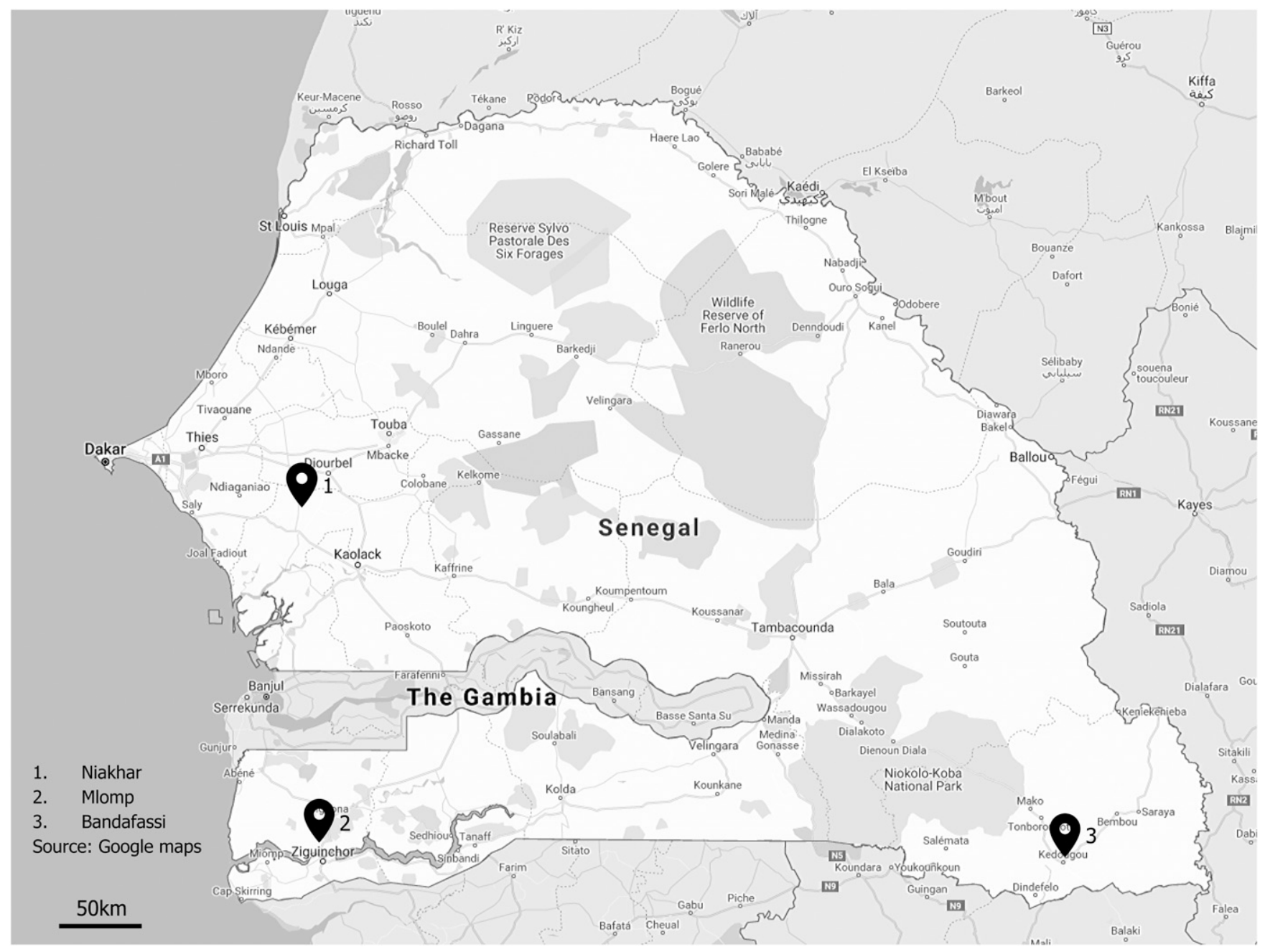

FIGURE 1. Study sites.

in larger villages and health outposts in smaller villages. ${ }^{22}$ Community health workers promote local health by linking health posts, outposts, and local populations. Because health posts provide primary outpatient, maternity care, and vaccination services, we focused on one per region.

Senegal offers prevention, screening, and treatment services for hepatitis $B$, but these services are unevenly distributed throughout the country. Since 2005, Senegal has included three doses of hepatitis $B$ vaccine in its combined (pentavalent) vaccine to infants at 6,10 , and 14 weeks of life. In 2016, it added a monovalent hepatitis B vaccine at birth (birth dose) to the infant immunization schedule. The National Hepatitis Programme, established in 2006 under the Ministry of Health, provides anti-HBV therapy (tenofovir) for HBV mono-infection, but access has been limited to Dakar's tertiary referral hospitals. The program now seeks decentralized screening and treatment services in the provinces.

Data collection. We pursued this study within the framework of the NéoVac (Neonatal Vaccination against Hepatitis B in Africa) study, which investigates the feasibility and impact of introducing timely birth dose vaccination against hepatitis $B$. The Senegal National Ethics Committee approved this study (SEN 16/36), and all participants provided written informed consent.
Data collection occurred between November 2016 and May 2018. In-depth semi-structured individual interviews and focus group discussions (FGDs) were used to collect data. Qualitative data collection targeted three population groups across the three sites: lay populations, formal health workers, and informal health workers.

Lay populations included pregnant women, fathers and mothers, and elder women living in the three health post catchment areas. Recruitment of study participants took place in two stages. In keeping with NéoVac study objectives of evaluating timely birth dose vaccination, we undertook snowball sampling, beginning with women receiving antenatal care or maternity services at the three health posts. We interviewed them in their home villages, and from these contacts, used purposive sampling to interview other mothers, fathers, and elder women outside of the health posts.

We targeted formal health workers (physicians, nurses, and midwives) and informal health workers (traditional healers, traditional birth attendants, community health workers, and bajenu gox, or village women serving as intermediaries with local health posts).

All semi-structured individual interviews were conducted with a pretested interview guide, a tool listing possible questions to be asked, depending on the informant's interests and 
expertise. Interviews, lasting between 25 and 70 minutes, were conducted and recorded in French or Wolof, or with the assistance of an experienced translator in Serer, Fulbé, or Diola languages.

Lay population interviews included two sets of questions: local explanations of the signs and symptoms of end-stage liver disease and knowledge of the term "hepatitis B" and its description. The first set focused on identifying local diagnostic categories related to signs and symptoms of end-stage liver disease by describing particular symptoms ("yellow eyes," abdominal swelling, and weight loss); informants could recount stories of acquaintances who suffered these illnesses, its consequences, diagnostic processes, referrals, and therapies. Because our qualitative investigation sought to understand chronic hepatitis $B$ sequelae from the perspectives of our informants, we did not evaluate the biomedical correctness of the descriptions, but rather considered any description of "the illness" related to signs and symptoms of end-stage liver disease. Interviews employed photo elicitation, using two photos of anonymized African patients, one male and one female with marked ascites due to decompensated cirrhosis secondary to chronic HBV infection. ${ }^{23,24}$ This strategy was useful in eliciting local interpretations of these symptoms. To gain insight into participants' interpretations of chronic hepatitis sequelae, we refrained from mentioning "hepatitis B" and posed no questions about it until after showing the photos, describing the symptoms, and asking for participants' interpretations of them. Formal and informal health worker interviews addressed knowledge of hepatitis B, its prevention and treatment, and local populations' understanding of diagnostic categories related to viral hepatitis.

We compared the FGDs with lay populations with the team's preliminary analyses of the semi-structured interviews. These discussions were also recorded. To ensure translation quality, recordings were transcribed verbatim from the languages that informants spoke by an experienced transcriber fluent in that language, and, if not conducted in French, were translated into French. This process also ensured continued quality of simultaneous translation during interviews.

Data analysis. We used qualitative content and discourse analysis for all data. ${ }^{25}$ After reading all transcriptions and notes, Sokhna Boye and Tamara Giles-Vernick developed codes together and transferred translated interviews, FGDs, and notes into NVivo (version 10, QSR International, London, England) qualitative analytical software. Sokhna Boye and Tamara Giles-Vernick each conducted an initial line-by-line coding, discussing and developing a consensus about initial coding. Together, all authors discussed and reorganized codes to synthesize and compare larger data segments for individual interviews and FGDs. Sokhna Boye and Tamara Giles-Vernick compared results generated by coding exercises of interviews and FGDs and wrote memos to analyze relationships between our data, codes, and analytical categories. Local explanations of hepatitis sequelae and logics underpinning individual participants' decision-making about their therapeutic pathways emerged from this analysis.

Qualitative data from individual interviews were recoded according to categorical variables and entered into an Excel spreadsheet to describe proportions of participants recognizing sequelae of chronic hepatitis and "hepatitis B."

\section{RESULTS}

Study participant characteristics. We conducted six focus groups and 149 individual interviews among 105 lay people and 31 informal and 13 formal health workers (Table 1). The median age of study participants was 40 years (range: 16-96 years); most (114/149) were women. Nearly two-thirds $(59 / 105)$ of the lay population and more than a third (11/31) of informal health workers had never received formal education. Study participants identified themselves according to diverse ethnic names, predominantly Serer and Diola.

Recognition of "hepatitis B" We present this result first because of the relatively homogeneous responses across different participant groups, although we posed questions about "hepatitis B" after those concerning signs and symptoms associated with end-stage liver disease. We find that hepatitis B is largely unknown among lay populations, somewhat more understood among informal health workers, and better recognized among formal health workers. Less than a third (30/105) of lay populations and nearly two-thirds $(18 / 31)$ of informal health workers indicated that they had heard of the term "hepatitis B" (Table 2). All formal health workers recognized this term; most (9/13) could describe something about hepatitis $\mathrm{B}$ and detail its consequences for those chronically infected, but four could not describe the disease at all.

Lay populations and informal health workers having heard of hepatitis $B$ had difficulties in describing it (Table 2). When asked about the illness, one Bandafassi mother first insisted that she had never heard of it, then recalled, "I have heard of it on the radio, but I wasn't paying attention to know exactly what it was. . I wasn't concentrating that day." However, few lay people could explain what it was, they could associate it with "liver damage" or "jaundice" or characterized it as "fatal," "cancerous," or "a little like AIDS, but different." Among informal health workers, more than a third (12/31) could describe "hepatitis B," mentioning abdominal swelling or jaundice, or describing it as "liver disease" or a "life-threatening condition."

Among those having heard of hepatitis $B$, formal and informal health workers received their information from other health workers. Formal health workers tended to receive some formal training that included information about hepatitis $B$,

TABLE 1

Number of people interviewed by study site

\begin{tabular}{|c|c|c|c|c|c|c|}
\hline \multirow[b]{2}{*}{ Study sites } & \multirow[b]{2}{*}{ All $(N=149)$} & \multicolumn{3}{|c|}{ Lay population $(n=105)$} & \multirow{2}{*}{$\begin{array}{l}\text { Informal health } \\
\text { workers } \neq(n=31)\end{array}$} & \multirow{2}{*}{$\begin{array}{c}\text { Formal health } \\
\text { workers } \S(n=13)\end{array}$} \\
\hline & & Young women ${ }^{\star}(n=57)$ & Elder woment $(n=25)$ & Fathers $(n=23)$ & & \\
\hline Niakhar & 79 & 33 & 16 & 13 & 14 & 3 \\
\hline Bandafassi & 30 & 10 & 4 & 4 & 5 & 7 \\
\hline Mlomp & 40 & 14 & 5 & 6 & 12 & 3 \\
\hline
\end{tabular}

* Young women include pregnant women and mothers of children aged $<5$ years.

$\dagger$ Elder women are those aged $>45$ years.

‡ Informal health workers include seven traditional healers, nine traditional birth attendants, five community health workers, and 10 bajenu gox.

$\S$ Formal health workers include one physician, eight nurses, and four midwives. 
TABLE 2

Knowledge of "hepatitis B"

\begin{tabular}{|c|c|c|c|c|}
\hline & All $(N=149)$ & $\begin{array}{l}\text { Lay population } \\
\qquad(n=105)\end{array}$ & $\begin{array}{l}\text { Informal health } \\
\text { workers }(n=31)\end{array}$ & $\begin{array}{c}\text { Formal health } \\
\text { workers }(n=13)\end{array}$ \\
\hline \multicolumn{5}{|l|}{ Knowledge of "hepatitis B" } \\
\hline Never heard & $88(59 \%)$ & $75(71 \%)$ & $13(42 \%)$ & 0 \\
\hline Ever heard but cannot describe & $32(22 \%)$ & $22(21 \%)$ & $6(19 \%)$ & $4(31 \%)$ \\
\hline Ever heard and can describe & $29(19 \%)$ & $8(8 \%)$ & $12(39 \%)$ & $9(69 \%)$ \\
\hline \multicolumn{5}{|c|}{ If you have heard of "hepatitis B," what was the source of information? } \\
\hline Health workers & $32(53 \%)$ & $9(30 \%)$ & $11(61 \%)$ & $12(92 \%)$ \\
\hline Radio & $14(23 \%)$ & $12(40 \%)$ & $2(11 \%)$ & 0 \\
\hline Family or friend & $5(8 \%)$ & $3(10 \%)$ & $2(11 \%)$ & 0 \\
\hline Do not recall & $10(16 \%)$ & $6(20 \%)$ & $3(17 \%)$ & $1(8 \%)$ \\
\hline
\end{tabular}

whereas informal health workers did not. Lay people knowing the term "hepatitis B" drew their information from the radio (12/ $30)$ or from health workers (9/30) (Table 2).

Lay explanations of chronic hepatitis sequelae. We sought to examine how lay people and informal health workers interpreted sequelae of chronic hepatitis $B$ (Table 3 ). About two-thirds (65/105) of lay people and more than a third (13/31) of informal health workers recognized and could describe an illness accounting for these signs and symptoms.

Local-language diagnostic terms, however, were highly diverse (Table 3), tending to draw from symptomatic descriptions and at times, etiologies. In keeping with qualitative interviews that permit reframing of questions, some lay populations and informal health workers initially responded that the illness was pëyis (Wolof), a diagnostic term evoking jaundice. This term appears to be part of a lexical field of illnesses evoking jaundice in multiple languages. Lay informants referred to pakiss, a Serer term linked to jaundice, as well as to fièvre jaune ("yellow fever," suggesting symptoms of jaundice).

Nevertheless, when follow-up questions emphasized other signs of illness, including abdominal swelling, respondents evoked other diagnostic categories as explanations. Bandafassi lay respondents used the Fulbé diagnostic terms danayel or yakou, invoking both swelling and paleness. Serer informants in the Niakhar region referred to symptoms of abdominal swelling using a pejorative term, "faa wagiir," literally "he is pregnant" or "a pregnant man." Finally, just two of 65 lay people and three of 23 informal health workers mentioned "hepatitis" as a cause of these symptoms.

These illnesses raised by lay populations in the three sites all have occult origins (a range of causes that include sorcery, poisoning, bad winds, and Satan). The manipulation of occult forces can cause harm to another person but may also compel that person to follow one's wishes. Evocation of occultcaused illness was expressed through the practice or idiom of "eating something" (dañuko lekulo in Wolof, or ka ñiamnin in Serer). For some lay informants, this "bad food" was "Satanic. . .but also, the wind can transmit it." Other informants suggested that a woman could seek the services of a diviner/ healer to control her husband, who might unwittingly ingest products causing abdominal swelling or edema. Sometimes, the consequences could be fatal to those who had "eaten" these substances, as one Niakhar man recounted:

\section{Participant}

One would say that someone consumed unhealthy food (" lékk bu baxul »). It could be done by a wife so that her husband would not take a second wife. . These are things that happen, things that exist. If you give to someone this type of product, sometimes a powder, that person won't ever digest it after having consumed it.

TABLE 3

Signs and symptoms related to chronic hepatitis sequelae: lay population and informal health workers recognition

\begin{tabular}{|c|c|c|c|}
\hline & All $(N=136)$ & $\begin{array}{l}\text { Lay population } \\
(n=105)\end{array}$ & $\begin{array}{l}\text { Informal health } \\
\text { workers }(n=31)\end{array}$ \\
\hline \multicolumn{4}{|c|}{ Do you recognize these signs and symptoms? } \\
\hline No & $52(38 \%)$ & $34(32 \%)$ & $18(58 \%)$ \\
\hline Yes, but I cannot describe what it is & $6(5 \%)$ & $6(6 \%)$ & 0 \\
\hline Yes, and I can describe what it is & $78(57 \%)$ & $65(62 \%)$ & $13(42 \%)$ \\
\hline \multicolumn{4}{|c|}{ How do you call these signs and symptoms? (multiple answer accepted) } \\
\hline Pëyis & $35(45 \%)$ & $32(49 \%)$ & $3(23 \%)$ \\
\hline Pakiss & $6(8 \%)$ & $4(6 \%)$ & $2(15 \%)$ \\
\hline Danayel & $4(5 \%)$ & $4(6 \%)$ & 0 \\
\hline Yakou & $4(5 \%)$ & $4(6 \%)$ & 0 \\
\hline Biir Buy Root & $1(1 \%)$ & 0 & $1(8 \%)$ \\
\hline Fièvre jaune & $5(6 \%)$ & $5(8 \%)$ & 0 \\
\hline Hépatite & $5(6 \%)$ & $2(3 \%)$ & $3(23 \%)$ \\
\hline Worms & $3(4 \%)$ & $3(5 \%)$ & 0 \\
\hline Liver disease & $3(4 \%)$ & $3(5 \%)$ & 0 \\
\hline Disease of Satan & $7(9 \%)$ & $6(9 \%)$ & $1(8 \%)$ \\
\hline Disease of the wind & $2(3 \%)$ & $2(3 \%)$ & 0 \\
\hline Pregnancy & $6(8 \%)$ & $5(8 \%)$ & $1(8 \%)$ \\
\hline Cancer & $7(9 \%)$ & $6(9 \%)$ & $1(8 \%)$ \\
\hline $\begin{array}{l}\text { Other (varied, including gut ailment } \\
\text { and insufficient vaccination) }\end{array}$ & $20(26 \%)$ & $17(26 \%)$ & $3(23 \%)$ \\
\hline
\end{tabular}




\section{Researcher}

\section{Do you mean that if the medicine is digested, the husband won't marry a second wife? And if he doesn't digest it, the man will fall ill?}

\section{Participant}

Maybe if her effort succeeds, the man won't take a second wife. You cannot know if you're eating it because the product is mixed into the dish. But there are people who can divine it by observing the symptoms of the illness.

Similar dynamics were also at play with women who inadvertently consumed such products. One elderly woman noted, "For women, it's the same. We would say that she has eaten something, or rather that she has been mystically afflicted."

Mlomp respondents similarly evoked occult etiologies for these symptoms, but several lay informants and health workers also suggested that gendered social transgressions could provoke swelling, weight loss, and jaundice. One elderly woman explained:

Before, when there weren't any hospitals, when a man presented these kinds of signs, we would say that he had seen a woman giving birth. Inversely, when it was a woman who fell ill with abdominal swelling, we said that she had seen the sacred forest. . .to see what was happening there. . . But these days, we know it's an illness that can affect anyone.

The reference to the "sacred forest," other informants indicated, evoked prohibitions on women witnessing male circumcision ceremonies, held in sacred forests. Such local explanations were stigmatizing because those suffering from these signs had committed a social transgression, witnessing events that they should not have.

IIIness consequences and therapeutic pathways. Lay populations and informal health workers perceived the local illness categories overlapping with the signs and symptoms of chronic hepatitis sequelae as serious, and frequently, mortal illnesses. One farmer from the Niakhar district couched the illness of "pregnant men" in a riddle: "When a man has this illness, we ask, 'Where is he going to give birth?' And we respond, 'In his tomb"' An elder woman averred, "it's a terrible illness...I don't know the cause, and I have forgotten the name. ....No [there is no cure]. But when it afflicts an older man or woman, that person dies."

In our three study sites, many lay people considered signs and symptoms of chronic hepatitis sequelae to be illnesses for which there was no biomedical treatment, and thus "not a hospital illness." Several informants insisted that seeking care at a biomedical structure was contraindicated. For some, injecting a patient with the illness pëyis, would not only be fruitless, but could hasten death. ${ }^{26,27}$ Older women in Bandafassi, referring to the illness as yakou, at once insisted that it "should be cared for traditionally" but then contended that the illness itself was incurable. As one observed, "I have never encountered anyone who was cured. ...I don't know anyone who came out of this illness alive. Nobody can cure this illness."
More generally, lay informants claimed, and "traditional" healers concurred, that local informal healers were the most appropriate health workers to consult. Healers prepared herbal infusions with specific plant roots or leaves for patients to drink or bathe with. The pakiss plant (Tinospora bakis), which grows as liana and shrub and whose name evokes the illness category describing jaundice, was a common treatment.

For other informants, however, the hospital could be the care option of last resort, particularly if treatments with local informal healers did not work. One elderly woman noted that "there are people who go to the hospital. . if the treatment doesn't provide results," whereas another recounted how her daughter, afflicted by abdominal swelling and weight loss, finally went to the hospital but died there.

\section{DISCUSSION}

Multiple questionnaire-based studies evaluating African lay public and health worker knowledge of "hepatitis B" or "viral hepatitis" have demonstrated that limited knowledge exists in multiple locations. ${ }^{9,15,28-30}$ We adopted a different investigative strategy, hypothesizing that lay populations may recognize visible signs and symptoms of sequelae of chronic HBV infection. We conducted a qualitative investigation to determine how rural Senegalese lay populations and formal and informal health workers understood these sequelae. Our point of departure was what these groups perceived and knew, rather than evaluating their knowledge as "correct" or "incorrect" from a biomedical standpoint. We found that lay publics did not recognize the term "hepatitis B," but when prompted through photo elicitation, were familiar with signs and symptoms of its sequelae. They found the combination of jaundice, ascites, and weight loss terrifying: these physical manifestations were linked to high mortality and in many cases, the manipulation of occult forces. For some, these symptoms carried social stigma. Many concluded that those developing these sequelae should seek traditional healers, not formal medical care.

Our investigation confirms findings of previous qualitative investigations showing that "hepatitis B" itself is not widely known and does not exist as a local illness category among subSaharan African populations. ${ }^{10,11,16,17}$ Informal health workers displayed relatively little recognition of hepatitis $B$, whereas a previous study in Burkina Faso demonstrated widespread recognition among "traditional" healers, who combine contemporary laboratory testing and sophisticated packaging of older herbal remedies. ${ }^{12}$ The present study investigated rural informal health workers, whereas the Burkina Faso study focused on urban informal health workers with greater access to formal health-care infrastructures and personnel and, thus, more opportunities for engagement around hepatitis B.

Lack of public knowledge of "hepatitis B" in Senegal and sub-Saharan Africa may result from public health communications that do not frame new information for meaningful integration into lay understandings of sequelae. ${ }^{12,17}$ Senegal's national program, for instance, produces media communications about hepatitis transmission and prevention and some lay respondents mentioned hearing of hepatitis $B$ on the radio. But these communications may not engage listeners, who have their own explanations of hepatitis sequelae. Similarly, a Central African Republic study found that although radio campaigns sought to raise awareness of hepatitis $B$ and routine childhood vaccination against it, lay people often 
collapsed all types of hepatitis into a single category ("hépatite") and forgot about vaccination; some traditional healers claimed to cure "hépatites $A, B, C$, D, et $E$," but acknowledged that they could not distinguish between them. ${ }^{13}$ Radio campaigns disseminated information that had no experiential meaning for audiences, who could not integrate and act on this knowledge.

Inaccessibility of testing and treatment and low visibility of preventive measures may also contribute to public lack of knowledge about hepatitis B. In Senegal, as elsewhere in Africa, specialist personnel, diagnostic testing, and monitoring are concentrated in urban centers, far from rural regions such as Niakhar, Mlomp, and Bandafassi. Preventive measures-routine hepatitis $B$ vaccination at birth and in early infancy-are frequently administered simultaneously with other vaccines, rendering these efforts to reduce hepatitis $B$ transmission less visible to parents.

Under such conditions, achieving high coverage of general population screening and successful linkage to biomedical monitoring and antiviral treatment may be challenging. A first step would be to enhance public awareness that the deadly consequences of hepatitis B infection can be avoided. Any communication campaign must be framed carefully and sensitively. Without reproaching lay publics for "incorrect" knowledge or "ignorance" of hepatitis B, campaigns should invoke local terms and descriptions. They should simultaneously avoid terms and description that are easily confused with other illnesses, particularly stigmatizing ones such as HIV. Campaigns promoting hepatitis B screening should be accompanied by appropriate pre- and posttest counseling services provided by trained health workers. ${ }^{3}$ Those testing positive for hepatitis B do not need to master the complex details of its natural history. Rather, post-test counseling can build on what people do know. A counselor can address the signs and symptoms of sequelae that lay publics recognize, use local terms that they use, and refer them to clinical staging and care services, including effective treatments to prevent their fatal consequences. Further work to develop and evaluate locally adapted communication tools to enhance linkage to care is needed in sub-Saharan Africa. ${ }^{14}$

A second, crucial concern involves health infrastructures and personnel to provide screening, clinical staging, and treatment services at prices affordable to people in lowincome countries. The best public health communications cannot address the fundamental disparities in access to diagnosis and care, either in Senegal or around the world. ${ }^{31}$ Studies in sub-Saharan Africa have demonstrated that the poorest people cannot afford health care for chronic viral hepatitis. ${ }^{32-34}$ Only investment reinforcing medical personnel, diagnostic equipment and laboratories, and access to treatment will enable people living with viral hepatitis to obtain regular follow-up and care.

Although less frequently used, qualitative investigations can contribute to viral hepatitis studies. Where people do not recognize "hepatitis B" or "viral hepatitis," questionnaires eliciting yes-no responses or checking off predetermined answers will shed little light on why they understand and act on this particular array of signs and symptoms as they do. Qualitative research, however, can reframe questions, dig further into informants' responses, and illuminate better the structures, motivations, and concepts shaping how people act when confronted with chronic viral hepatitis sequelae. Photo elicitation, although widely used in qualitative research, has not to our knowledge been used in studies of chronic viral hepatitis.

This study has limitations. Our attention to specific signs and symptoms necessarily entailed a broad focus on the sequelae of viral hepatitis, including chronic infection with hepatitis $\mathrm{C}$ virus $(\mathrm{HCV})$, or possibly another disease with a different etiology, including liver cancer from high alcohol consumption. We could not explicitly link responses to hepatitis B. Nonetheless, in Senegal, seroprevalence of HCV infection $(1 \%)$ is 10 times lower than that of chronic HBV infection $(11 \%),{ }^{35}$ and alcohol consumption is low. ${ }^{36}$ We also conducted no interviews with those suffering from sequelae of chronic HBV infection because we aimed to investigate knowledge through a rural community study with snow-ball sampling, a study design entailing challenges in identifying and interviewing patients with end-stage liver disease.

Finally, anthropologists have criticized investigations focusing exclusively on diagnostic categories, contending that such studies neglect these categories' broader significance and their relations to other domains of life. ${ }^{37}$ We concur. Nevertheless, our study highlights one neglected dimension of tackling the challenges of viral hepatitis in sub-Saharan Africa; we present one part of a broader investigation situating this knowledge in a wider array of practices and relations.

\section{CONCLUSION}

The high disease burden of hepatitis B in sub-Saharan Africa makes it a crucial global health priority, and the WHO's global strategy provides an important roadmap for elimination by 2030 . To achieve its goals, screening and treatment services must be accessible by the world's poorest and most affected populations. These services also require lay populations' full engagement with screening, linkage to care, and lifelong treatment. Our study reveals that Senegalese lay populations and informal and formal health workers widely recognize sequelae of chronic HBV infection. Strengthening communications about diagnosis and care for viral hepatitis can build on this widespread recognition and can contribute to reducing Africa's viral hepatitis burden.

Received June 26, 2019. Accepted for publication December 3, 2019. Published online January 20, 2020.

Acknowledgments: We are grateful to all participants in the study for their careful responses to our many questions and for their time. Aissatou Traoré provided excellent research assistance in Niakhar. We also thank Cheikh Sokhna, Aldiouma Diallo, El Hadji Bah, Cassandre von Platen, Sandrine Fernandes Pellerin, Magali Herrant, and Joy Cremesty for their support.

Financial support: The NéoVac project was funded by the Total Foundation.

Authors' addresses: Sokhna Boye and Muriel Vray, Unité d'Epidémiologie des Maladies Infectieuses, Institut Pasteur de Dakar, Dakar, Senegal, E-mails: sokhnaboye@gmail.com and murielvray@hotmail.com. Yusuke Shimakawa, Emerging Diseases Epidemiology Unit, and Tamara GilesVernick, Anthropology and Ecology of Disease Emergence, Pasteur Institute, Paris, France, E-mails: yusuke.shimakawa@pasteur.fr and tamara.giles-vernick@pasteur.fr.

\section{REFERENCES}

1. WHO, 2016. Global Health Sector Strategy on Viral Hepatitis 2016-2021. Geneva, Switzerland: World Health Organization. 
2. WHO, 2017. Global Hepatitis Report, 2017. Geneva, Switzerland: World Health Organization.

3. WHO, 2017. Guidelines on Hepatitis B and C Testing. Geneva, Switzerland: World Health Organization.

4. Ishizaki A, Bouscaillou J, Luhmann N, Liu S, Chua R, Walsh N, Hess S, Ivanova E, Roberts T, Easterbrook P, 2017. Survey of programmatic experiences and challenges in delivery of hepatitis $\mathrm{B}$ and $\mathrm{C}$ testing in low- and middle-income countries. BMC Infect Dis 17 (Suppl 1): 696.

5. Schweitzer A, Horn J, Mikolajczyk RT, Krause G, Ott JJ, 2015. Estimations of worldwide prevalence of chronic hepatitis B virus infection: a systematic review of data published between 1965 and 2013. Lancet 6736: 1-10.

6. Polaris Observatory Collaborators, 2018. Global prevalence, treatment, and prevention of hepatitis B virus infection in 2016: a modelling study. Lancet Gastroenterol Hepatol 3: 383-403.

7. Whittle $\mathrm{HC}$, Inskip $\mathrm{H}$, Bradley $\mathrm{AK}$, McLaughlan $\mathrm{K}$, Shenton $\mathrm{F}$, Lamb W, Eccles J, Baker BA, Hall AJ, 1990. The pattern of childhood hepatitis B infection in two Gambian villages. J Infect Dis 161: 1112-1115.

8. Kiire CF, 1996. The epidemiology and prophylaxis of hepatitis $B$ in sub-Saharan Africa: a view from tropical and subtropical Africa. Gut 38 (Suppl 2): S5-S12.

9. Lemoine $\mathrm{M}$ et al., 2016. Acceptability and feasibility of a screenand-treat programme for hepatitis B virus infection in the Gambia: the Prevention of Liver Fibrosis and Cancer in Africa (PROLIFICA) study. Lancet Glob Health 4: e559-e567.

10. Pourette D, Enel C, 2014. Representations and disease experience of hepatitis B by sub-Saharan patients in Ivory Coast and France. Sante Publique (Paris) 26: 869-878.

11. Enel C, Desgrées du Loû A, N'Dri Yoman T, Danel C, Larmarange $J, 2015$. Viral hepatitis $B$ and $C$ in Ivory Coast: stepping up the fight, a pressing need. J Afr Hépatol Gastroentérol 9: 94-98.

12. Giles-Vernick T, Hejoaka F, Sanou A, Shimakawa Y, Bamba I, Traore A, 2016. Barriers to linkage to care for hepatitis $B$ virus infection: a qualitative analysis in Burkina Faso, west Africa. Am J Trop Med Hyg 95: 1368-1375.

13. Giles-Vernick T, Traoré A, Bainilago L, 2016. Incertitude, hepatitis $B$ and infant vaccination in west and central Africa. Med Anthropol Q 30: 203-221.

14. Shimakawa Y, Pourette D, Bainilago L, Enel C, Sombié R, Rado R, Lemoine M, Giles-Vernick T, 2017. Improving communication about viral hepatitis in Africa. Lancet Infect Dis 17: 688-689.

15. Jaquet $A$, Wandeler G, Tine J, Diallo MB, Manga NM, Dia NM, Fall $F$, Dabis F, Seydi M, 2017. Prevention and care of hepatitis B in Senegal: awareness and attitudes of medical practitioners. Am J Trop Med Hyg 97: 389-395.

16. Chabrol F, Noah Noah D, Tchoumi EP, Vidal L, Kuaban C, Carrieri MP, Boyer S; EVOLCam group, 2019. Screening, diagnosis and care cascade for viral hepatitis $B$ and $C$ in Yaoundé, Cameroon: a qualitative study of patients and health providers coping with uncertainty and unbearable costs. BMJ Open 9: e025415.

17. Mkandawire P, Richmond C, Dixon J, Luginaah IN, Tobias J, 2013. Hepatitis B in Ghana's upper west region: a hidden epidemic in need of national policy attention. Health Place 23: 89-96.

18. Shimakawa Y et al., 2016. Natural history of chronic HBV infection in west Africa: a longitudinal population-based study from the Gambia. Gut 65: 2007-2016.

19. Shimakawa $Y$ et al., 2015. The prevalence and burden of symptoms in patients with chronic liver diseases in the Gambia, west Africa. Palliat Med 29: 184-185.
20. Mokaya J, McNaughton AL, Burbridge L, Maponga T, O'Hara G, Andersson M, Seeley J, Matthews PC, 2018. A blind spot? Confronting the stigma of hepatitis B virus (HBV) infection - a systematic review. Wellcome Open Res 3: 29.

21. United Nations Development Reports, 2018. Human Development Reports. Senegal. Available at: http://hdr.undp.org/en/ countries/profiles/SEN. Accessed April 30, 2019.

22. Ministère de la Santé et de l'Action Sociale. Le Système de Santé du Sénégal se Présente sous Forme d'une Pyramide de Trois Niveaux. Available at: http://www.sante.gouv.sn/politique-desante/pyramide-de-santé. Accessed April 30, 2019.

23. Harper D, 2002. Talking about pictures: a case for photo elicitation. Vis Stud 17: 13-26.

24. Padgett DK, Smith BT, Derejko K-S, Henwood BF, Tiderington $\mathrm{E}, 2013$. A picture is worth ... .? Photo elicitation interviewing with formerly homeless adults. Qual Health Res 23: 14351444.

25. Forman J, Creswell JW, Damschroder L, Kowalski CP, Krein SL, 2008. Qualitative research methods: key features and insights gained from use in infection prevention research. Am J Infect Control 36: 764-771.

26. Jaffré Y, Olivier de Sardan J-P, 1999. La Construction Sociale Des Maladies: Les Entités Nosologiques Populaires En Afrique de l'Ouest. Paris, France: Presses Universitaires de France.

27. Ndoye T, 2009. La Société Sénégalaise Face Au Paludisme Politiques, Savoirs et Acteurs. Paris, France: Karthala.

28. Debes JD, Kayandabila J, Pogemiller H, 2016. Knowledge of hepatitis $\mathrm{B}$ transmission risks among health workers in Tanzania. Am J Trop Med Hyg 94: 1100-1102.

29. Qin Y-L et al., 2018. Prevalence and associated knowledge of hepatitis B infection among healthcare workers in Freetown, Sierra Leone. BMC Infect Dis 18: 315.

30. Nankya-Mutyoba J, Aizire J, Makumbi F, Atuyambe L, Ocama P, Kirk GD, 2018. Correlates of hepatitis B awareness and disease-specific knowledge among pregnant women in Northern and Central Uganda: a cross-sectional study. Hepatol Med Policy 3: 14.

31. Pfeiffer J, Nichter M; Critical Anthropology of Global Health Special Interest Group, 2008. What can critical medical anthropology contribute to global health? A health systems perspective. Med Anthropol Q 22: 410-415.

32. Chabrol F, David P-M, Krikorian G, 2017. Rationing hepatitis C treatment in the context of austerity policies in France and Cameroon: a transnational perspective on the pharmaceuticalization of healthcare systems. Soc Sci Med 187: 243-250.

33. Chabrol F, 2018. Viral hepatitis and a hospital infrastructure in ruins in Cameroon. Med Anthropol 37: 645-658.

34. Anfaara FW, Atuoye KN, Mkandawire P, Luginaah I, 2018. Factors associated with voluntary testing for HBV in the upper west region of Ghana. Health Place 54: 85-91.

35. Riou J, Aït Ahmed M, Blake A, Vozlinsky S, Brichler S, Eholié S, Boëlle PY, Fontanet A; HCV Epidemiology in Africa Group, 2016. Hepatitis $C$ virus seroprevalence in adults in Africa: a systematic review and meta-analysis. $J$ Viral Hepat 23: 244-255.

36. Jaquet A, Tchounga B, Tanon A, Bagny A, Ekouevi DK, Traore HA, Sasco AJ, Maiga M, Dabis F, 2018. Etiology of hepatocellular carcinoma in west Africa, a case-control study. Int $\mathrm{J}$ Cancer 143: 869-877.

37. Lambert H, McKevitt C, 2002. Anthropology in health research: from qualitative methods to multidisciplinarity. BMJ 325: 210213. 